\title{
Iodine-induced hyperthyroidism in a patient with a normal thyroid gland
}

\author{
Shmuel Shilo and Harry J. Hirsch
}

Shaare Zedek Medical Centre, Jerusalem 91002, Israel

\begin{abstract}
Summary: Iodine-induced hyperthyroidism can develop even in the presence of an otherwise normal gland. One of the less common sources of iodine is tablets of seaweed, sold over the counter without prescription. We report the case of a 72 year old female who developed clinical and laboratory evidence of hyperthyroidism while ingesting sea-kelp (Vitalia) tablets. Six months after stopping the tablets, the symptoms and laboratory evidence of hyperthyroidism had disappeared. No evidence of pre-existing thyroid disease was found.
\end{abstract}

\section{Introduction}

It is well accepted that iodine may cause hyperthyroidism (Fradkin \& Wolff, 1983) even in patients who do not have any evidence of underlying thyroid disease (Savoie et al., 1975). The sources of iodine can be inorganic iodine added to food such as bread, organic iodine in radiographic contrast agents or certain drugs. Seaweed which is sold over the counter can also cause hyperthyroidism.

\section{Case report}

A 72 year old woman was referred because of typical complaints of hyperthyroidism, including weight loss of about $5 \mathrm{~kg}$ during the previous 6 months in spite of a normal appetite, excess sweating, fatigue and several soft stools a day. There was no history of thyroid disease in her family or her past and no evidence of iodine deficiency in her area. During the previous year she had been taking 4-6 tablets of sea-kelp (Vitalia, Norway), each tablet containing $0.7 \mathrm{mg}$ of iodine, a total of $2.8-4.2 \mathrm{mg}$ iodine per day.

Physical examination revealed diffuse enlargement of the thyroid without a bruit. Thyroid function tests (Table I) were compatible with a diagnosis of hyperthyroidism. The radioactive uptake $\left({ }^{131} \mathrm{I}\right.$ uptake) value was very low after 2 and 24 hours and a thyroid scan with technetium $99 \mathrm{~m}$ was normal. There was complete suppression of thyrotrophin stimulating hormone (TSH) after injection of $200 \mu \mathrm{g}$ thyrotrophin releasing hormone (TRH). Thyroid antibodies were undetectable. Erythrocyte sedimentation rate and routine

Correspondence: S. Shilo, M.D.

Accepted: 3 January 1986 haematology and biochemistry were normal. The patient was advised to stop the sea-kelp tablets after which her complaints disappeared, she gained weight and her thyroid gland became no longer palpable. Six months after stopping the sea-kelp tablets plasma levels of thyroid hormones had returned to normal and a normal TSH response to TRH administration was observed.

\section{Discussion}

Iodine-induced hyperthyroidism has frequently followed iodine repletion in many endemic iodine deficient areas of the world (Fradkin \& Wolff, 1983). Iodine-induced hyperthyroidism occurs in patients with autonomous thyroid nodules (Maderos-Neto et al., 1975), congenital or endemic goitre, goitre with an autonomous hot nodule (Savoie et al., 1975) and nontoxic nodular goitre (Liewendahl \& Gordin, 1974). All these observations suggest that an increased incidence of hyperthyroidism is due to an increased supply of iodine to patients with either underlying autonomous thyroid nodules or underlying Graves' disease.

According to Savoie et al. (1975) the main features of this phenomenon are: (1) the development of hyperthyroidism after iodine ingestion for at least one month; (2) lack of known pathology in the thyroid gland; (3) enlargement of the thyroid only during hyperthyroidism; (4) low iodine uptake; (5) disappearance of hyperthyroidism and regression in thyroid gland with cessation of iodine ingestion; (6) in some cases temporary development of hypothyroidism, and (7) no pathological finding in the thyroid gland after recovery.

(C) The Fellowship of Postgraduate Medicine, 1986 
Table I Thyroid function tests before and after stopping the seaweed

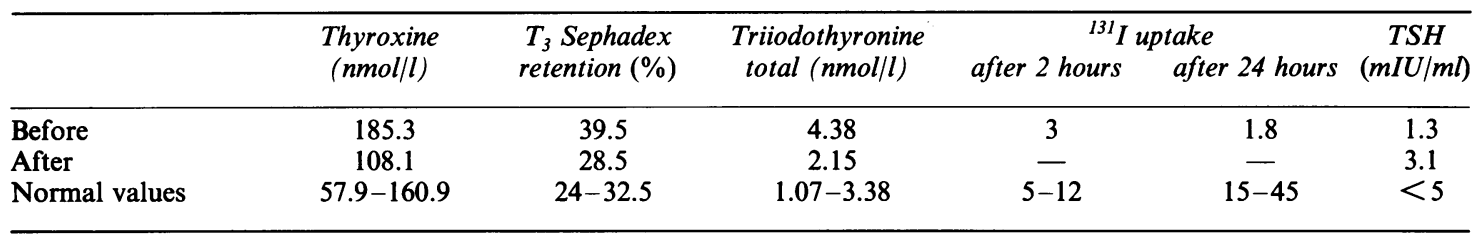

In our patient we could rule out a hot nodule or multinodular goitre from the physical examination and thyroid scan. Graves' disease could be ruled out because of the low radioactive iodine uptake. Factitious hyperthyroidism could explain the thyroxine elevation, the low iodine uptake and the cure after stopping the tablets, but the history and the patient's personality did not suggest this possibility. The absence of pain in the neck or tenderness in the gland region, normal body temperature, and normal sedimentation rate are against the diagnosis of subacute thyroiditis which is also characterized by raised blood $T_{4}$ and $T_{3}$ and low radioiodine uptake. $A$

\section{References}

ADAMS, D.P., KENNEDY, T.H., STEWARD, J.C., UTIGER, R.O. \& VIDOR, G.I. (1975). Hyperthyroidism in Tasmania following iodine supplementation, measurement of thyroid stimulating autoantibodies. Journal of Clinical Endocrinology and Metabolism, 41, 221.

FRADKIN, J.E. \& WOLFF, J. (1983). Iodide induced thyrotoxicosis. Medicine, $62,1$.

LIEWENDAHL, K. \& GORDIN, A. (1974). Iodine induced toxic diffuse goiter. Acta Medica Scandinavica, 196, 237. history of iodine ingestion - a major point of differentiation between iodine-induced hyperthyroidism and silent thyroiditis (Fradkin \& Wolff, 1983) - was also present in our case.

The pathophysiology of iodine-induced hyperthyroidism is not clear. The early concepts included underlying thyroid pathology which did not show itself because of iodine deficiency. With the addition of the iodine to the diet, signs of hyperthyroidism start to appear (Adams et al., 1975). It is postulated that defective autoregulation of hormone biosynthesis may contribute to iodine-induced hyperthyroidism (Fradkin \& Wolff, 1983).
MADEROS-NETO, G.A., PENNA, M., MONTEIRO, K. KATAOKA, K., IMAI, Y. \& HOLLANDER, C. (1975). TheO effect of iodized oil on TSH response to TRH in endemic goiter patients. Journal of Clinical Endocrinology ands Metabolism, 41, 504.

SAVOIE, J.C.,MASSIN, J.P., THOMOPOULOS, P. \& LEGER, T. (1975). Iodine induced thyrotoxicosis in apparently normal thyroid glands. Journal of Clinical Endocrinology and Metabolism, 41, 685. 